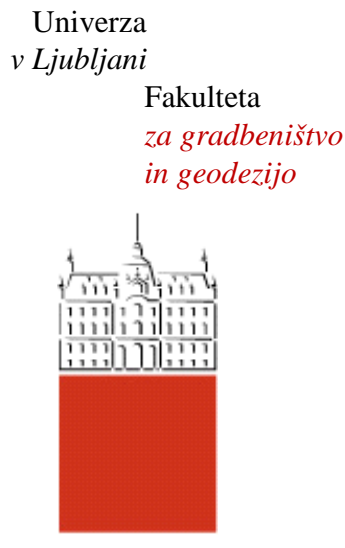

Jamova 2

1000 Ljubljana, Slovenija http://www3.fgg.uni-lj.si/

DRUGG - Digitalni repozitorij UL FGG http://drugg.fgg.uni-lj.si/

Ta članek je avtorjeva zadnja recenzirana različica, kot je bila sprejeta po opravljeni recenziji.

Prosimo, da se pri navajanju sklicujete na bibliografske podatke, kot je navedeno:
University

of Ljubljana

Faculty of

Civil and Geodetic

Engineering

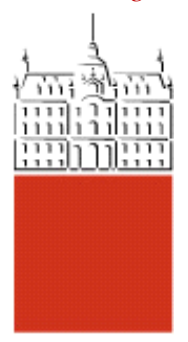

Jamova 2

SI - 1000 Ljubljana, Slovenia

http://www3.fgg.uni-lj.si/en/

DRUGG - The Digital Repository http://drugg.fgg.uni-lj.si/

This version of the article is author's manuscript as accepted for publishing after the review process.

When citing, please refer to the publisher's bibliographic information as follows:

Bratina, S., Planinc, I., Saje, M. in Turk G. 2003. Non-linear fire-resistance analysis of reinforced concrete beams. Structural engineering and mechanics 16, 6: 695-712. 


\title{
Non-linear fire-resistance analysis of reinforced concrete beams
}

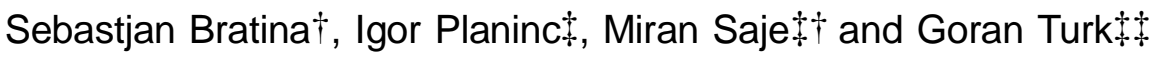 \\ University of Ljubljana, Faculty of Civil and Geodetic Engineering, Jamova 2, \\ Sl-1115 Ljubljana, Slovenia
}

(Received February 24, 2003, Accepted September 26, 2003)

\begin{abstract}
The non-linear structural analysis of reinforced concrete beams in fire consists of three separate steps: (i) The estimation of the rise of surrounding air temperature due to fire; (ii) the determination of the distribution of the temperature within the beam during fire; (iii) the evaluation of the mechanical response due to simultaneous time-dependent thermal and mechanical loads. Steps (ii) and (iii) are dealt with in the present paper. We present a two-step computational procedure where a $2 \mathrm{D}$ transient thermal analysis over the cross-sections of beams are made first, followed by mechanical analysis of the structure. Fundamental to the accuracy of the mechanical analysis is a new planar beam finite element. The effects of plasticity in concrete, and plasticity and viscous creep in steel are taken into consideration. The properties of concrete and steel along with the values of their thermal and mechanical parameters are taken according to the European standard ENV 1992-1-2 (1995). The comparison of our numerical and full-scale experimental results shows that the proposed mechanical and 2D thermal computational procedure is capable to describe the actual response of reinforced concrete beam structures to fire.
\end{abstract}

Key words: fire design; heat conduction; Reissner beam; finite element method; reinforced concrete; creep.

\section{Introduction}

The performance-based approach to the design of structures under fire conditions is a preferable method with respect to prescriptive approach used in the past. A large amount of experimental, analytical, and numerical research has been performed to support the use of performance-based approach and to expand the knowledge of fire loading and the behaviour of structures under fire. Most of experiments have been limited to tests on a single element of a structure under controlled conditions, e.g. Ellingwood and Lin (1991), Gustaferro et al. (1971), Lin et al. (1981) and Lin et al. (1988). Experiments are performed in specially designed furnaces in which the temperature of surrounding air follows the design fire temperature curves; these are prescribed by standards, such as the ASTM Standard E119 (1976), ISO 834 (1999), or SDHI (1980) (see Fig. 1). There are also

$\dagger$ Research Assistant

$\$$ Assistant Professor

$\neq \dagger$ Professor, and the correspondent

按 Associate Professor 


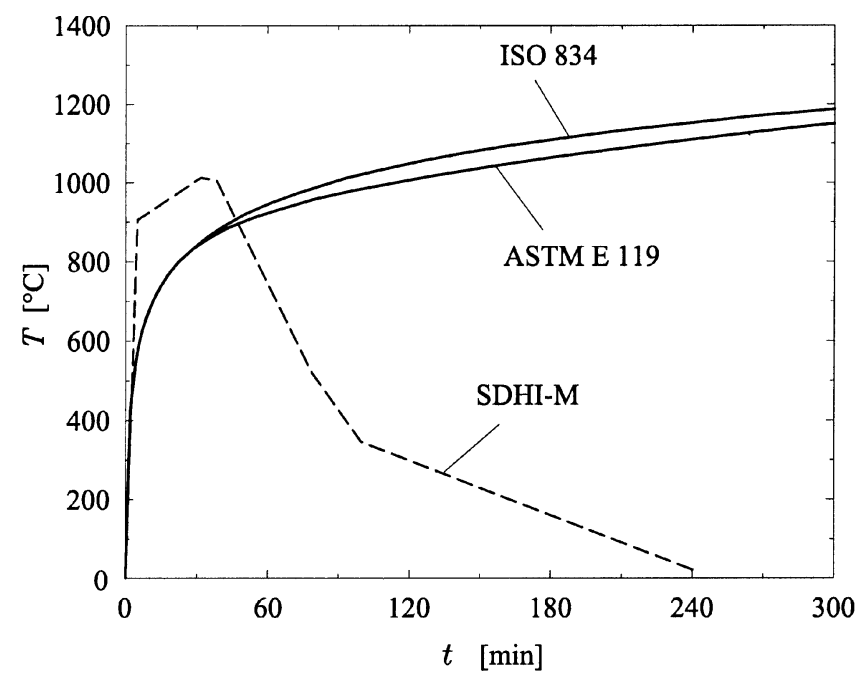

Fig. 1 Furnace atmosphere temperature for ASTM, ISO, and SDHI fire

reports on full-scale fire tests on more complex structures, such as multistory buildings. These tests not only make possible to assess the actual behaviour of the structure, but also identify additional mechanisms that may develop during fire in complex structures (see, e.g. Armer and O'Dell 1996, and Lennon et al. 2000).

The theoretical analysis of the structural behaviour under fire conditions consists of several steps. In the first step, we have to identify the characteristics of fire, such as its type and extent. The spread of fire is affected by several factors which are difficult to identify reliably and their influence and interaction are even more difficult to predict. We will not discuss these issues in the present paper. The next step is the estimation of the heat transfer from fire into the structure. If the structure is directly exposed to fire, radiation is the pre-dominant type of the heat transfer. If the structure or its part is in the shadow from fire, the heat transfers through the air by the forced or natural convection. If temperature in one part of the structure increases, the heat transfers through the structure by conduction. In order to determine the temperature distribution within the structure, all three phenomena should be considered in the analysis. A simplified analysis is usually performed in which the heat conduction problem, governed by the partial differential equation of heat conduction, is solved while the effect of heat radiation and convection from fire to the structure is taken into account only by boundary conditions. In such an analysis it is important to note that material parameters are strongly temperature dependent in the temperature range of fire (see, e.g. Abrams 1977, Harmathy 1970, Lie and Irwin 1993). In the present analysis a 2D finite element computer programme developed by Saje and Turk (1987) is applied to determine the temperature distribution over the cross-section of the structure. In the case of concrete and timber structures, there exists an additional phenomenon which may considerably affect the temperature distribution: the elements of structures may not be oven-dry. Therefore, water tries to evaporate from the structure which may cause a considerable delay in temperature rise at temperatures about $100^{\circ} \mathrm{C}$. The delay is clearly visible in some experimental data, see Gustaffero et al. (1971). Computational models that account for this phenomenon have been proposed by several authors (among others, Budaiwi et al. 1999, Lie and Irwin 1993, Vasile et al. 1998). 
In the final step, we have to estimate the mechanical response of the structure. The deformation of the structure is caused by shrinkage, creep, temperature strains, changing mechanical properties, mechanical loads, etc. There are various computational models for the mechanical analysis of the frame-like structure, e.g. the elastic model (often suggested by standards), the visco-elastic model, the rigid-plastic model, the visco-elastic-plastic model.

Also, the structure can be modelled by 1D, 2D or 3D elements. The more advanced non-linear fire analyses are based on the 2D and 3D finite elements (see, e.g. Huang et al. 1997, Nechnech et al. 2002). The 3D theories are computationally very demanding and are at present limited to the prediction of the fire resistance of only simple concrete members. Therefore, most researchers base their analyses of reinforced concrete frame structures exposed to fire on beam finite elements and the plane section hypothesis (see, e.g. Ellingwood et al. 1991, Lie et al. 1993, Sidibé et al. 2000).

In this paper, we present the two-step computational procedure for the non-linear thermomechanical analysis of reinforced concrete planar beams subjected to fire. Fundamental to the mechanical analysis is a new and very efficient planar beam finite element derived by Planinc et al. (2001). The physical, material and geometric non-linearity of the beam as well as temperature dependent material properties are taken into account.

\section{Heat conduction}

The temperature distribution $T\left(x_{1}, x_{2}, x_{3}\right)$ at time $t$ is governed by the differential equation of heat conduction

$$
\mathscr{V}: \quad \sum_{i=1}^{3} \frac{\partial}{\partial x_{i}}\left(\sum_{j=1}^{3} k_{i j} \frac{\partial T}{\partial x_{j}}\right)+Q-\rho c \frac{\partial T}{\partial t}=0
$$

and the boundary conditions

$$
\mathscr{\varphi}_{T}: \quad T_{s}-T=0
$$

on surface $\mathscr{S}_{T}$ where the temperature, $T_{s}$, is prescribed, and

$$
\mathscr{S}_{q}: \quad \sum_{i=1}^{3} \sum_{j=1}^{3} k_{i j} \frac{\partial T}{\partial x_{i}} n_{j}-q_{s}=0
$$

on surface $\mathscr{S}_{q}$ where the heat flow, $q_{s}$, is prescribed. The initial temperature distribution in the structure must be known:

$$
\mathscr{V}: \quad T\left(x_{1}, x_{2}, x_{3}, 0\right)=T_{0}\left(x_{1}, x_{2}, x_{3}\right)
$$

Material parameters $k_{i j}, \rho$, and $c$ denote the symmetric tensor of the conductivity, the density, and the specific heat, respectively. $Q$ is the specific volumetric heat source, in concrete often due to the heat of hydration, some other chemical reaction in material, or plastic deformations. As already indicated, Cartesian coordinates are denoted by $x_{1}, x_{2}, x_{3}$, whereas the components of the unit 
normal to the surface of the structure are denoted by $n_{1}, n_{2}, n_{3}$. The prescribed heat flow at the surface may be decomposed into several parts

$$
q_{s}=q_{c}+q_{r}+q_{f}+q_{i}
$$

where $q_{c}, q_{r}, q_{f}$ and $q_{i}$ are the convection, the radiation, the fire induced and the insolation parts of the surface heat flow, respectively. The convection part is usually assumed to be a linear function of the difference between the surrounding air temperature and the temperature at the surface of the structure

$$
q_{c}=h_{c}\left(T_{A}-T\right)
$$

where $h_{c}$ is the convection heat transfer coefficient, which depends on the wind speed, the shape of the structure, roughness of the surface, etc. (Özişik 1985). Heat flow due to the radiation depends on the geometric shape of the structure and the radiative body. It is usually assumed to follow the Stefan law, see, e.g. Özişik (1985):

$$
q_{r}=\varepsilon_{r} B\left(T_{r}^{4}-T^{4}\right)
$$

where $T_{r}$ is the absolute temperature of the radiative body, $T$ is the absolute temperature of the body surface, $\varepsilon_{r}$ is the emissivity, and $B$ the Stefan-Boltzmann constant.

The heat flow due to the solar radiation is given by a simple equation (Dilger et al. 1983)

$$
q_{i}=I_{s c} k_{T} a \cos \theta
$$

where $I_{s c}$ is the solar constant, $k_{T}$ is the air transmissivity factor which depends on the air pollution, the date and the height above the sea level, $a$ is the surface absorption coefficient, and $\theta$ is the inclination angle which depends on the space orientation of the boundary surface, the date, the geographic latitude and the height above the sea level. In assessing the effect of fire, the influence of the insolation is neglected.

Alternatively, the effect of fire can be accounted for by a single comprehensive term $q_{f}$ (see, e.g. Mendes et al. 2000), which is the function of the emissive power of fire, an atmospheric transmissivity, the shape of the structure, the distance from fire, etc. We do not follow this approach here.

A large set of experiments has been performed by several research groups, and they all indicate that thermal properties of concrete are strongly temperature dependent (see, e.g. Abrams 1977 , Harmathy 1970). According to the European code EVN 1992-1-2 (1995), the conductivity, the specific heat and the density depend on temperature by the following relations:

$$
\begin{array}{cc}
k_{c}(T)=1.6-0.16 \frac{T}{120}+0.008\left(\frac{T}{120}\right)^{2} & {\left[\frac{W}{\mathrm{~m}^{\circ} \mathrm{C}}\right],} \\
c_{c}(T)=900+80 \frac{T}{120}-4\left(\frac{T}{120}\right)^{2} & {\left[\frac{J}{\mathrm{~kg}^{\circ} \mathrm{C}}\right],}
\end{array}
$$




$$
\rho_{c}(T)=\left\{\begin{array}{ll}
2400, & 20^{\circ} \mathrm{C} \leq T \leq 100^{\circ} \mathrm{C} \\
2300, & 100^{\circ} \mathrm{C}<T \leq 1200^{\circ} \mathrm{C}
\end{array} \quad\left[\mathrm{kg} / \mathrm{m}^{3}\right] .\right.
$$

Thermal properties of steel reinforcement are not given because the effect of reinforcement on the heat conduction in concrete is only minor and therefore was not considered.

The solution of the boundary value problem (1) and (2)-(4) was obtained numerically by the finite element method (Saje and Turk 1987).

\section{The mechanical analysis of a planar beam}

\subsection{Basic equations of a straight planar beam}

The present finite element formulation is based on Reissner's kinematically exact model of the beam (Reissner 1972). It is assumed that the compatibility of deformations at the contact of the reinforcement bar and concrete holds. Large membrane and flexural deformations are allowed in the analysis, whereas shear strains are small and their effect can be neglected.

The stress-strain state of the beam of initial length $L$ is analysed in the plane $x, z$ of the Cartesian coordinate system $x, y, z$. The $x$-axis coincides with the centroidal axis of the undeformed beam element $(x \in[0, L])$. The beam element is assumed to be loaded by a time-dependent temperature over the cross-section, by conservative distributed forces $p_{x}$ and $p_{z}$, conservative distributed moment $m_{y}$, and generalised conservative concentrated loads at the ends of the beam element, $S_{i}(i=1,2, \ldots, 6)$ (see Fig. 2).

The so called 'geometric' (or total) extensional strain, $D$, of an arbitrary fibre is a function of extensional strain of the centroidal axis $\varepsilon$ (membrane deformation), and its pseudocurvature $\kappa$ (flexural deformation). In Reissner's beam model geometric extensional strain is linear with respect to $z$

$$
D(x, z)=\varepsilon(x)+z \kappa(x),
$$

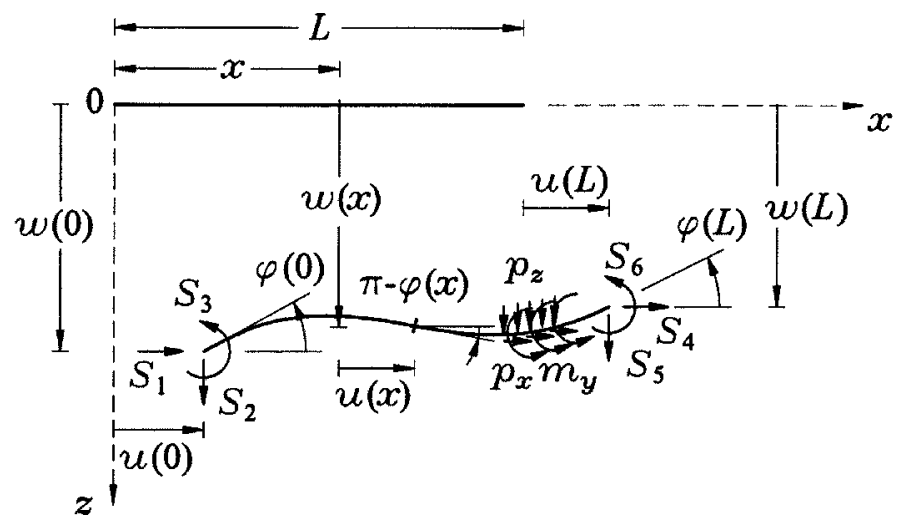

Fig. 2 Beam element in the initial and deformed state 
and it is assumed to be the sum of mechanical extensional strain, thermal strain and viscous strain. The deformation quantities, $\varepsilon, \kappa$, are related to the kinematic ones, $u, w, \varphi$, by the kinematic equations (Reissner 1972):

$$
\begin{gathered}
1+u^{\prime}-(1+\varepsilon) \cos \varphi=0, \\
w^{\prime}+(1+\varepsilon) \sin \varphi=0, \\
\varphi^{\prime}-\kappa=0,
\end{gathered}
$$

where the prime (') denotes the derivative with respect to $x$. In Eqs. (12)-(14), $u$ and $w$ are displacements of the centroidal axis in the $x$ - and $z$-directions, and $\varphi$ is its rotation about the $y$-axis.

The equilibrium generalised internal forces, $\mathcal{N}, \mathcal{Q}, \mathcal{M}$, and the conservative distributed loads, $p_{x}$, $p_{z}, m_{y}$, of the element are related by the equilibrium equations

$$
\begin{gathered}
(\mathcal{N} \cos \varphi+\mathcal{Q} \sin \varphi)^{\prime}+p_{x}=\mathcal{R}_{1}^{\prime}+p_{x}=0 \\
(-\mathcal{N} \sin \varphi+\mathcal{Q} \cos \varphi)^{\prime}+p_{z}=\mathcal{R}_{2}^{\prime}+p_{z}=0 \\
\mathcal{M}^{\prime}-(1+\varepsilon) \mathcal{Q}+m_{y}=0
\end{gathered}
$$

The third set of basic equations is provided by the constitutive law. Two equations of the constitutive law are used to relate the equilibrium quantities, $\mathcal{N}$, and $\mathcal{M}$, with the constitutive internal forces, $\mathcal{N}_{c}$ and $\mathcal{M}_{c}$, via the deformation quantity $D_{m}$ :

$$
\begin{aligned}
\mathcal{N}-\mathcal{N}_{c} & =0, & \mathcal{N}_{c} & =\int_{A} \sigma\left(D_{m}\right) d A, \\
\mathcal{M}-\mathcal{M}_{c} & =0, & \mathcal{M}_{c} & =\int_{A} z \sigma\left(D_{m}\right) d A .
\end{aligned}
$$

It can easily be derived from (18)-(19) that the constitutive quantities, $\mathcal{N}_{c}$ and $\mathcal{M}_{c}$, depend on a chosen material model which is defined by the relationship between the longitudinal normal stress, $\sigma$, and the mechanical extensional strain, $D_{m}$, of a longitudinal fibre. The relationship must be determined experimentally.

\subsection{Modified principle of virtual work}

Eqs. (12)-(19) together with the corresponding boundary conditions constitute a set of eight nonlinear equations for eight unknowns: two deformation functions $\varepsilon(x)$ and $\kappa(x)$, three equilibrium quantities $\mathcal{R}_{1}(x)=\mathcal{N} \cos \varphi+\mathcal{Q} \sin \varphi, R_{2}(x)=-\mathcal{N} \sin \varphi+\mathcal{Q} \cos \varphi$ and $\mathcal{M}(x)$, and three kinematic functions $u(x), w(x)$ and $\varphi(x)$. Analytical solutions are known only for some very elementary cases which may serve for the verification of numerical procedures. Generally, the problem has to be solved numerically, in this case by the finite element method. A beam finite element has been derived by the use of the modified $\mathrm{Hu}$-Washizu functional 


$$
\begin{gathered}
\delta W^{*}=\int_{0}^{L}\left(\mathcal{N}_{c}-\mathcal{N}\right) \delta \varepsilon d x+\int_{0}^{L}\left(\mathcal{M}_{c}-\mathcal{M}\right) \delta \kappa d x+ \\
\left(\varphi(L)-\varphi(0)-\int_{0}^{L} \kappa d x\right) \delta \mathcal{M}(0)+ \\
\left(u(L)-u(0)-\int_{0}^{L}(1+\varepsilon) \cos \varphi d x+L\right) \delta \mathcal{R}_{1}(0)+ \\
\left(w(L)-w(0)+\int_{0}^{L}(1+\varepsilon) \sin \varphi d x\right) \delta \mathcal{R}_{2}(0)- \\
\left(S_{1}+\mathcal{R}_{1}(0)\right) \delta U_{1}-\left(S_{2}+\mathcal{R}_{2}(0)\right) \delta U_{2}-\left(S_{3}+\mathcal{M}(0)\right) \delta U_{3}- \\
\left(S_{4}-\mathcal{R}_{1}(L)\right) \delta U_{4}-\left(S_{5}-\mathcal{R}_{2}(L)\right) \delta U_{5}-\left(S_{6}-\mathcal{M}(L)\right) \delta U_{6}=0
\end{gathered}
$$

where $u(0), u(L), \ldots, \varphi(L)$ are the generalised kinematic quantities at the two ends of the finite element. The modified principle of virtual work is very suitable for materially non-linear problems, since the deformation quantities, $\varepsilon(x)$ and $\kappa(x)$, are the only functions involved, whereas displacements, $u(x), w(x)$, rotation $\varphi(x)$, equilibrium forces $\mathcal{R}_{1}(x), \mathcal{R}_{2}(x)$ and equilibrium moment $\mathcal{M}(x)$ are represented in functional (20) only by their boundary values.

\subsection{The finite element formulation}

In our previous formulation (Planinc et al. 2001), we assumed that $\mathcal{N}_{\mathrm{c}}-\mathcal{N}=0$. Therefore only $\kappa(x)$ was interpolated. In the present paper, both strain measures, extensional strain $\varepsilon(x)$ and pseudocurvature $\kappa(x)$ of the centroidal axis, are interpolated over the finite element length. We use the Lagrangian interpolation through equidistant nodes. Thus,

$$
\begin{array}{cc}
\varepsilon(x)=\sum_{n=1}^{N_{\varepsilon}} P_{n \varepsilon}(x) \varepsilon_{n}, & \delta \varepsilon(x)=\sum_{n=1}^{N_{\varepsilon}} P_{n \varepsilon}(x) \delta \varepsilon_{n}, \\
\kappa(x)=\sum_{n=1}^{N_{\kappa}} P_{n \kappa}(x) \kappa_{n}, & \delta \kappa(x)=\sum_{n=1}^{N_{\kappa}} P_{n \kappa}(x) \delta \kappa_{n},
\end{array}
$$

where $\varepsilon_{n}\left(n=1,2, \ldots, N_{\varepsilon}\right)$ and $\kappa_{n}\left(n=1,2, \ldots, N_{\kappa}\right)$ are nodal extensional strains and pseudocurvatures, respectively, and $\delta \varepsilon_{n}$ and $\delta \kappa_{n}$ are their variations. $P_{n \varepsilon}$ and $P_{n \kappa}$ are the Lagrangian polynomials of orders $N_{\varepsilon}-1$ and $N_{\kappa}-1$, respectively.

After expressions (21)-(22) are introduced into functional (20), the Euler-Lagrange equations of the finite element are obtained. There are $N_{\varepsilon}+N_{\kappa}+9$ non-linear algebraic equations for $N_{\varepsilon}+N_{\kappa}+9$ unknowns of the form $\boldsymbol{G}(\boldsymbol{x}, \lambda)=\boldsymbol{R}(\boldsymbol{x})-\lambda \boldsymbol{P}=\mathbf{0}$, where $\boldsymbol{x}$ is the vector of unknowns of the element, and $\lambda$ is the loading factor. Among the unknowns, there are $N_{\varepsilon}+N_{\kappa}+3$ internal degrees of freedom $\varepsilon_{n}\left(n=1,2, \ldots, N_{\varepsilon}\right), \kappa_{n}\left(n=1,2, \ldots, N_{\kappa}\right), \mathcal{R}_{1}(0), \mathcal{R}_{2}(0)$, and $\mathcal{M}(0)$, and six external degrees of freedom $u(0), u(L), w(0), w(L), \varphi(0), \varphi(L)$ of the element.

In the analysis of reinforced concrete structures under fire conditions, where the geometric and material non-linearity is taken into account, the algebraic system of non-linear equations when written for the structure needs to be solved by an incremental-iterative way. The time interval $[0, t]$ is divided into time steps $\left[t^{j-1}, t^{j}\right]$. For each step $j$ and a given loading factor increment $\Delta \lambda^{j}$, the 
iterative corrections of nodal displacements, $\delta x_{i+1}^{j}$, are determined by Newton's iterative method $(i=1,2, \ldots)$

$$
\boldsymbol{K}\left(x_{i}^{j}, \Delta \lambda^{j}, T^{j}, t^{j}\right) \delta \boldsymbol{x}_{i+1}^{j}+\boldsymbol{G}\left(x_{i}^{j}, \Delta \lambda^{j}, T^{j}, t^{j}\right)=\mathbf{0}
$$

where $\boldsymbol{K} \equiv \nabla_{x} \boldsymbol{G}$ is a tangent stiffness matrix of the structure. The corrections of displacement increments $\Delta \boldsymbol{x}_{i+1}^{j}$ at the end of time step $j$ and the loading factor are determined by the equations

$$
\begin{gathered}
\Delta \boldsymbol{x}_{i+1}^{j}=\Delta \boldsymbol{x}_{i}^{j}+\delta \boldsymbol{x}_{i+1}^{j}, \\
\boldsymbol{x}_{i+1}^{j}=\boldsymbol{x}^{j-1}+\Delta \boldsymbol{x}_{i+1}^{j}, \\
\lambda^{j}=\lambda^{j-1}+\Delta \lambda^{j} .
\end{gathered}
$$

\subsection{The decomposition of the geometric strain increment}

The geometric, i.e. total extensional strain increment $\Delta D^{j}$ is assumed to be the sum of mechanical extensional strain increment $\Delta D_{m}^{j}$ and thermally induced strain increment $\Delta D_{T}^{j}$. In addition, a part of geometric extensional strain of the steel reinforcement is attribute to the influence of viscous creep in steel, $\Delta D_{C}^{j}$. Thus,

$$
\begin{gathered}
\text { for concrete: } \Delta D^{j}=\Delta D_{c m}^{j}+\Delta D_{c T}^{j} \rightarrow \Delta D_{c m}^{j}=\Delta D^{j}-\Delta D_{c T}^{j} ; \\
\text { for steel: } \Delta D^{j}=\Delta D_{s m}^{j}+\Delta D_{s T}^{j}+\Delta D_{C}^{j} \rightarrow \quad \Delta D_{s m}^{j}=\Delta D^{j}-\Delta D_{s T}^{j}-\Delta D_{C}^{j} .
\end{gathered}
$$

\subsection{Numerical computional procedure}

In Box 1 the numerical computional procedure to determine the mechanical behaviour of reinforced concrete planar beams due to simultaneous action of static and fire load is presented. The detail evaluation of several strain components is shown in the next chapter.

\section{Mechanical properties of concrete and steel}

\subsection{The constitutive law of concrete and steel}

The mechanical part of the geometric extensional strain increment, $\Delta D_{m}$, does not directly depend on temperature or time. It is related to the longitudinal normal stress by a constitutive law. The reliability of results of a fire analysis is strongly affected by the choice of the constitutive law and the values of its parameters. Again the parameters are temperature dependent (see, e.g. Abrams 1977, and Harmathy 1970).

In the present analysis, the constitutive law for concrete is used according to the European standard ENV 1992-1-2 (1995) (Fig. 3): 
Box 1 Numerical computional procedure

TIME STEP $\left[t^{j-1}, t^{j}\right]$ :

$$
\begin{gathered}
t^{j}=t^{j-1}+\Delta t^{j}, \quad T^{j}=T^{j-1}+\Delta T^{j}, \quad \lambda^{j}=\lambda^{j-1}+\Delta \lambda^{j}, \\
\Delta D_{c T(s T)}^{j}=D_{c T(s T)}^{j}-D_{c T(s T)}^{j-1}
\end{gathered}
$$

- Structure level - Newton's iterative method $(i=1,2, \ldots)$ :

- Element level: initial displacement increments $\Delta \boldsymbol{x}_{i=1}^{j}=0$

- Reinforcing bar $\left(y_{s}^{k}, z_{s}^{k}\right)$ of cross-section with coordinate $x$ on centroidal axis:

Newton's iterative method to evaluate $\Delta \sigma_{s, i}^{j}\left(D_{s m, i}^{j}\right)$ and $\Delta D_{C, i}^{j}\left(\sigma_{s, i}^{j}\right)$

- Element level at cross-section: $\mathcal{N}_{c, i}^{j}$ and $\mathcal{M}_{c, i}^{j}$

$\circ$ The tangent stiffness matrix of the element $\boldsymbol{K}_{e l}$ and corresponding loading vector $\boldsymbol{G}_{e l}$ :

$$
\begin{aligned}
& \boldsymbol{K}_{e l}\left(\boldsymbol{x}^{j-1}+\Delta \boldsymbol{x}_{i}^{j}, \lambda^{j}, T^{j}, t^{j}\right) \\
& \boldsymbol{G}_{e l}\left(\boldsymbol{x}^{j-1}+\Delta \boldsymbol{x}_{i}^{j}, \lambda^{j}, T^{j}, t^{j}\right)
\end{aligned}
$$

- The tangent stiffness matrix of the structure $\boldsymbol{K}=\nabla_{x} \boldsymbol{G}$ and corresponding loading vector $\boldsymbol{G}$ :

$$
\begin{aligned}
& \boldsymbol{K}\left(\boldsymbol{x}^{j-1}+\Delta \boldsymbol{x}_{i}^{j}, \lambda^{j}, T^{j}, t^{j}\right) \\
& \boldsymbol{G}\left(\boldsymbol{x}^{j-1}+\Delta \boldsymbol{x}_{i}^{j}, \lambda^{j}, T^{j}, t^{j}\right)
\end{aligned}
$$

- The corrections of displacement increments:

$$
\begin{gathered}
\delta \boldsymbol{x}_{i+1}^{j}=-K^{-1} \boldsymbol{G} \\
\Delta \boldsymbol{x}_{i+1}^{j}=\Delta \boldsymbol{x}_{i}^{j}+\delta \boldsymbol{x}_{i+1}^{j}
\end{gathered}
$$

- Stop iteration if:

$$
\begin{gathered}
\delta \boldsymbol{x}_{i+1}^{j}<\text { prescribed precision } \\
\boldsymbol{x}_{i+1}^{j}=\boldsymbol{x}^{j-1}+\Delta \boldsymbol{x}_{i+1}^{j}
\end{gathered}
$$

$$
\sigma_{c}= \begin{cases}0, & D_{c m}>0 \text { or } D_{c m}<D_{c u}(T) \\ -f_{c}(T)\left(\frac{D_{c m}}{D_{c 1}(T)} \frac{3}{2+\left(\frac{D_{c m}}{D_{c 1}(T)}\right)^{3}}\right), & D_{c u}(T) \leq D_{c m} \leq 0\end{cases}
$$

Temperature dependent mechanical characteristics of concrete according to this law are: ultimate strain $D_{c u}$, compressive strength $f_{c}$, and strain at compressive strength $D_{c 1}$. The beneficiary effect of small tensile strength of the concrete is at this stage of research neglected. The stress increment in concrete in the $i^{\text {th }}$ iteration of time step $\left[t^{j-1}, t^{j}\right]$ is determined by the equation

$$
\Delta \sigma_{c, i}^{j}=\sigma_{c}\left(D_{c m, i}^{j}\right)-\sigma_{c}\left(D_{c m}^{j-1}\right) .
$$

The constitutive law of the steel reinforcement is also taken according to the European standard 


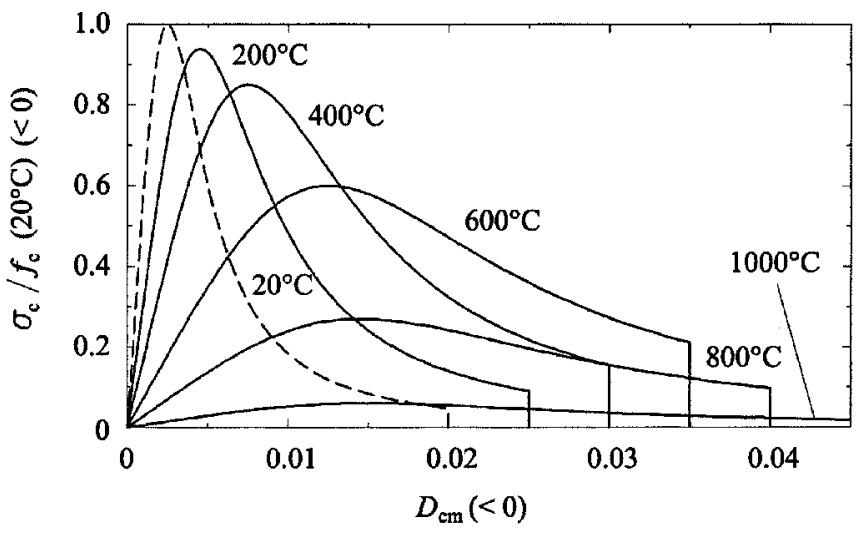

(a) Stress-strain relations for concrete

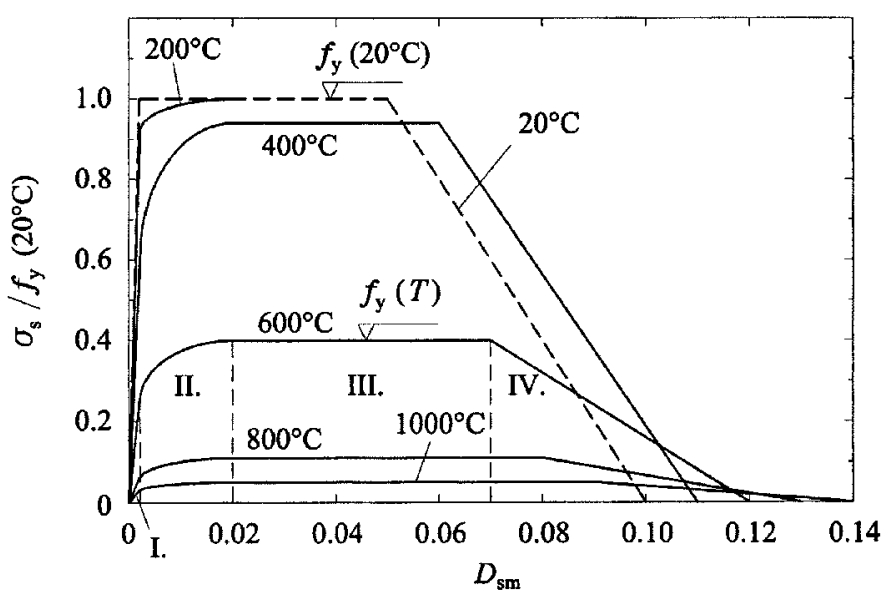

(b) Stress-strain relations for steel

Fig. 3 Stress-strain relations for concrete and steel at various temperatures

ENV 1992-1-2 (1995). There, the stress-strain law is described by four functions, as indicated in Fig. 3, and given by the relations

$$
\sigma_{s}= \begin{cases}E_{s}(T) D_{s m} & \ldots \mathrm{I} \\ \operatorname{sgn}\left(D_{s m}\right)\left(\frac{b(T)}{a(T)} \sqrt{a(T)^{2}-\left(0.02-\left|D_{m}\right|\right)^{2}}+\sigma_{s p r}(T)-c(T)\right) & \ldots \mathrm{II} \\ \operatorname{sgn}\left(D_{s m}\right) f_{y}(T) & \ldots \mathrm{III} \\ \operatorname{sgn}\left(D_{s m}\right) f_{y}(T)\left(1-\frac{\left|D_{s m}\right|-D_{y 2}|T|}{D_{y u}(T)-D_{y 2}(T)}\right) & \ldots \mathrm{IV} \\ 0 & \ldots \mathrm{V}\end{cases}
$$

where I, II, III, IV, and V are the domains defined by: 


$$
\begin{array}{ll}
\text { I... } & 0 \leq\left|D_{s m}\right| \leq \frac{\sigma_{s p r}(T)}{E_{s}(T)}, \\
\text { II... } & \frac{\sigma_{s p r}(T)}{E_{s}(T)} \leq\left|D_{s m}\right| \leq 0.02, \\
\text { III... } & 0.02<\left|D_{m}\right| \leq D_{y 2}(T), \\
\text { IV... } & D_{y 2}(T)<\left|D_{s m}\right| \leq D_{y u}(T), \\
\text { V... } & \left|D_{s m}\right|>D_{y u}(T) .
\end{array}
$$

The temperature dependent steel parameters are: elastic modulus, $E_{s}$; elastic limit stress, $\sigma_{s p r}$; yield stress, $f_{y}$; strain at yield stress, $D_{y 2}$; and ultimate strain of steel, $D_{y u}$. Precise functional relations between the above listed parameters as well as the parameters $a, b$, and $c$, and temperature are given in the European standards ENV 1992-1-2 (1995). The stress increment in the reinforcement in $i^{\text {th }}$ iteration of $j^{\text {th }}$ time step $\left[t^{j-1}, t^{j}\right]$ is determined from the equation

$$
\Delta \sigma_{s, i}^{j}=\sigma_{s}\left(D_{s m, i}^{j}\right)-\sigma_{s}\left(D_{s m}^{j-1}\right)
$$

\subsection{Thermal deformation of concrete and steel}

When a piece of material is heated or cooled, its dimensions increase and decrease which results in thermal strains. We assume thermal strains according to European standards ENV 1992-1-2 (1995) (Fig. 4). The thermal strain, $D_{c T}$, for concrete with calcareous aggregates, as a function of temperature, is given by

$$
D_{c T}(T)=\left\{\begin{array}{lr}
-1.2 \cdot 10^{-4}+6 \cdot 10^{-6} T+1.4 \cdot 10^{-11} T^{3}, & 20^{\circ} \mathrm{C} \leq T \leq 805^{\circ} \mathrm{C} \\
12 \cdot 10^{-3}, & 805^{\circ} \mathrm{C}<T \leq 1200^{\circ} \mathrm{C}
\end{array}\right.
$$

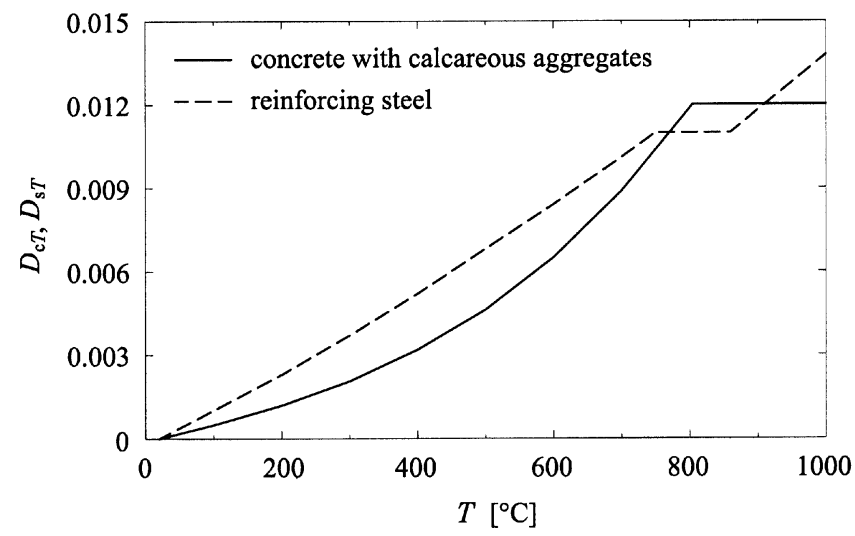

Fig. 4 Thermal strain of concrete and reinforcement 
Similarly, the thermal strain for reinforcing steel, $D_{s T}$, is given by

$$
D_{s T}(T)=\left\{\begin{array}{lr}
-2.416 \cdot 10^{-4}+1.2 \cdot 10^{-5} T+0.4 \cdot 10^{-8} T^{2}, & 20^{\circ} \mathrm{C} \leq T \leq 750^{\circ} \mathrm{C} \\
11 \cdot 10^{-5}, & 750<C T \leq 860^{\circ} \mathrm{C} \\
-6.2 \cdot 10^{-3}+2 \cdot 10^{-5} T, & { }^{\circ}<T \leq 1200^{\circ} \mathrm{C}
\end{array}\right.
$$

The expressions (29)-(30) are used to determine the thermal strain increments in $j^{\text {th }}$ time step for concrete

$$
\Delta D_{c T}^{j}=D_{c T}^{j}-D_{c T}^{j-1}
$$

and likewise for the reinforcing steel

$$
\Delta D_{s T}^{j}=D_{s T}^{j}-D_{s T}^{j-1}
$$

\subsection{Viscous creep strain in steel reinforcement}

The viscous creep strain in steel is negligible if the temperature is moderate. Only if the temperature of steel exceeds $400^{\circ} \mathrm{C}$, the strain rate becomes considerable. There are a number of creep models available. In our research, the Williams-Leir model is chosen (Williams-Leir 1983). The original model offers analytical expressions for viscous creep strain under constant stress and temperature. After an appropriate modification has been completed, the model can also be used for changing temperature and stress, see Srpčič (2000). Viscous creep strain $D_{C}^{j}$ at the end of time step $\left[t^{j-1}, t^{j}\right]$ is determined by the following equation

$$
b_{2} D_{C}^{j}-\tanh \left(b_{2} D_{C}^{j}\right)-b_{2} D_{C}^{j-1}+\tanh \left(b_{2} D_{C}^{j-1}\right)-\frac{b_{2}}{\eta} \int_{T^{j-1}}^{T^{j}} b_{1}(\theta) d \theta=0 \text {. }
$$

The related viscous creep strain increment is given by

$$
\Delta D_{C}^{j}=D_{C}^{j}-D_{C}^{j-1}
$$

where $D_{C}^{j-1}$ is the viscous creep strain at time $t^{j-1}$, coefficients $b_{1}$ and $b_{2}$ in (33) are given functions of stress, temperature and some additional material constants to be determined by the laboratory experiments. Parameter $\eta=\Delta T / \Delta t$ is the average rate of temperature change in a time step. Non-linear Eq. (33) is solved numerically by Newton's method, while the integral in (33) is evaluated numerically.

\section{Numerical example}

The proposed numerical method is verified by the comparison of numerical results to the results of a full-scale laboratory test of a simply supported reinforced concrete beam exposed to the ASTM 119 standard fire load (Gustaferro et al. 1971). Geometric, material and loading data are given in 


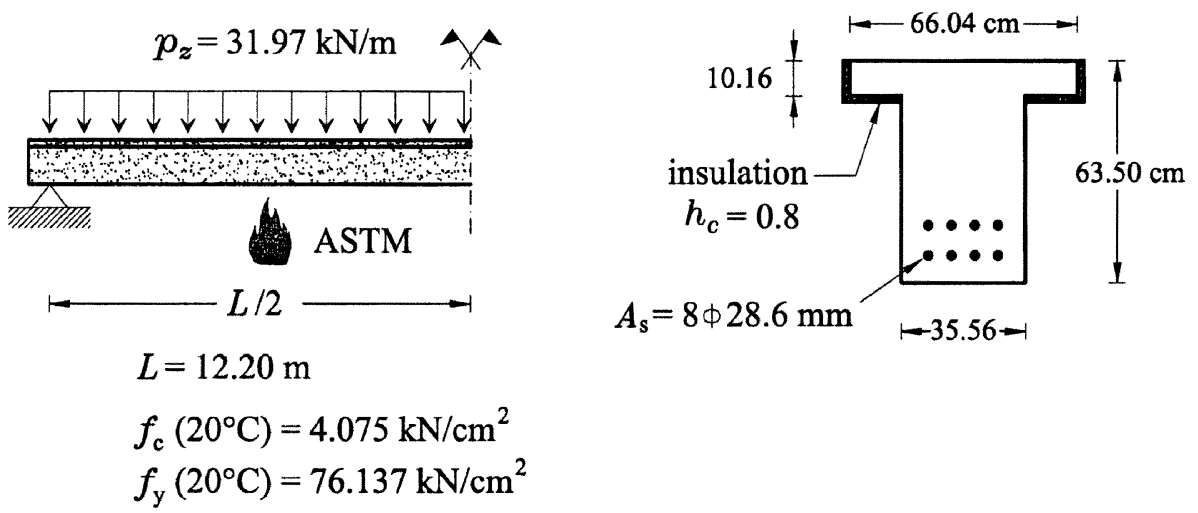

Fig. 5 A simply supported beam (Gustaferro et al. 1971)

Fig. 5. In the experiment, the web of the beam was exposed to hot air with the temperature changing according to the ASTM standard fire curve, allowing for the tolerances of $\pm 1^{\circ} \mathrm{C}$. The flange was isolated from the bottom and lateraly, whereas the upper side of the flange was not exposed to fire or isolated. The thermal properties of concrete and steel used in the experiment are not given in Gustaferro et al. (1971); therefore, these values are assumed to follow the European standard ENV 1992-1-2 (1995) (see Eqs. (8)-(10)). The heat transfer coefficient is assumed to be $h_{c}=25 \mathrm{~W} /\left(\mathrm{m}^{2 \circ} \mathrm{C}\right)$ for the exposed surfaces, and $h_{c}=9 \mathrm{~W} /\left(\mathrm{m}^{2 \circ} \mathrm{C}\right)$ for the upper surface. For the isolated part of the flange, $h_{c}$ is taken to be $0.8 \mathrm{~W} /\left(\mathrm{m}^{20} \mathrm{C}\right.$ ) (see Eq. (5)). The emissivity of the concrete surface was not determined in the experiment and is here assumed to be either $\varepsilon_{r}=0.56$ or $\varepsilon_{r}=0.3$ (see Eq. (6)). The fire induced part of the surface heat flow $\left(q_{f}\right)$ and the solar radiation part $\left(q_{i}\right)$ was neglected and have no effect on temperature distribution.

It is further assumed that the heat transfer in the longitudinal direction is sufficiently small compared to the heat transfer across the cross-section, so that it can be neglected. Consequently, only the 2D transient heat conduction problem over a typical cross-section governed by partial differential Eq. (1) is solved. A computer programme based on the finite element method is used (Saje and Turk 1987). The cross-section is modelled by 796 four-node finite elements and 873 nodes (Fig. 6a), which we find to be sufficient for our purposes.

The beam is modelled by two beam finite elements described previously, for which the extensional strain, $\varepsilon$, and the pseudocurvature, $\kappa$, are interpolated by the Lagrangian polynomials of the fourth order, whereas the numerical integration along the element is performed by the five-point Lobatto integration rule. The integration of $\mathcal{N}_{c}, \mathcal{M}_{c}$, and the cross-sectional tangent stiffnesses over the cross-section is performed by the Gaussian integration (using $3 \times 3$ integration points) over 12 sectors (Fig. 6b).

The reduced value of emissivity, $\varepsilon_{r}=0.3$, gives better results for temperature development in time; this is indicated in Fig. 7, where the temperatures in the least and the most exposed bars are shown.

The actual time to failure as measured in experiment is 373 minutes, and the related vertical displacement is $66 \mathrm{~cm}$. If viscous effects in steel are neglected, and the reduced emissivity 0.3 employed, the numerically estimated vertical displacement at 373 minutes is $52.77 \mathrm{~cm}$ (curve A in Fig. 8), which is considerably better than the displacement $85.11 \mathrm{~cm}$ obtained for higher value of emissivity 0.56 (the curve is not shown in Fig. 8). 
(a)

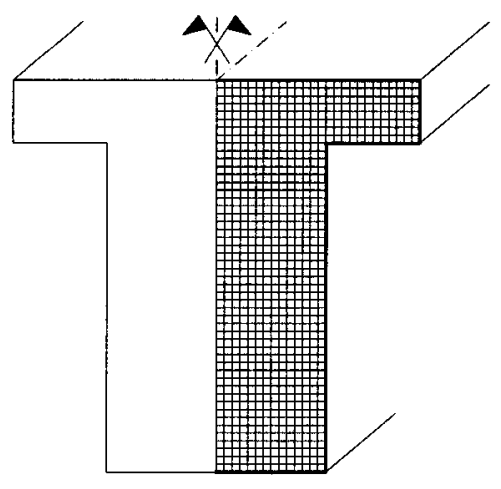

(b)

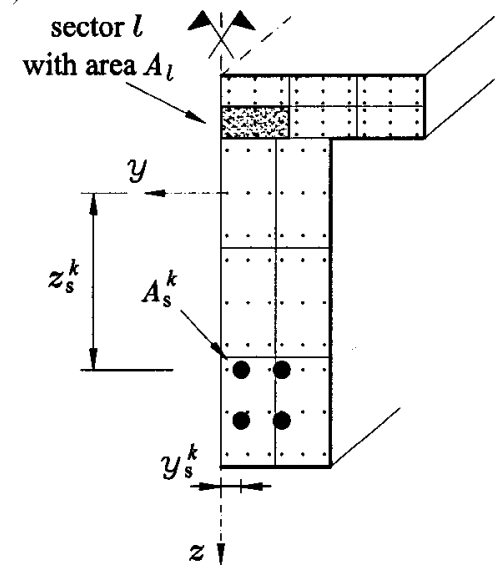

Fig. 6 (a) Finite element mesh for heat conduction analysis, (b) stress integration scheme over cross-section

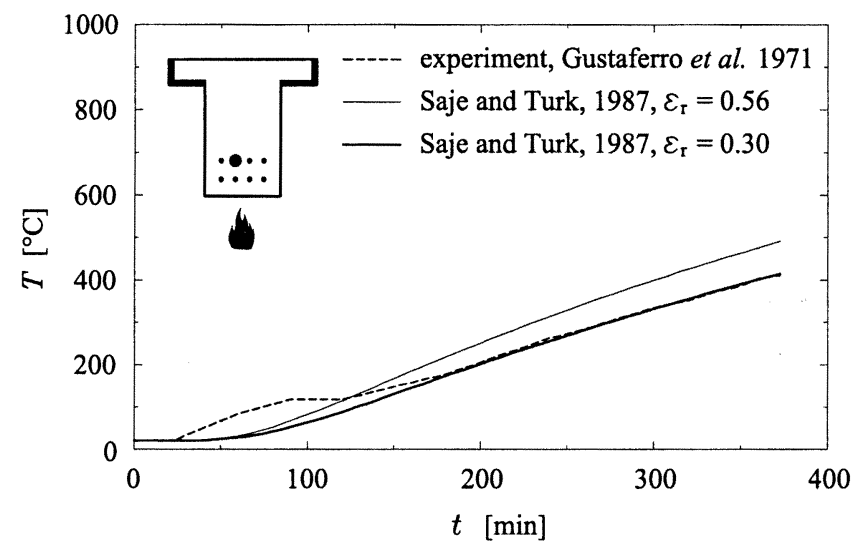

(a) The least exposed reinforcing bar

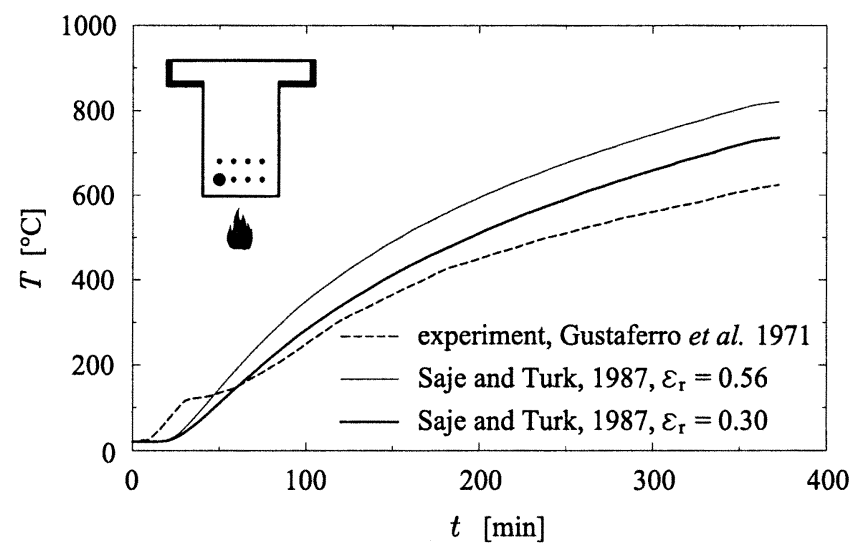

(b) The most exposed reinforcing bar

Fig. 7 Temperature increase in two reinforcement bars 


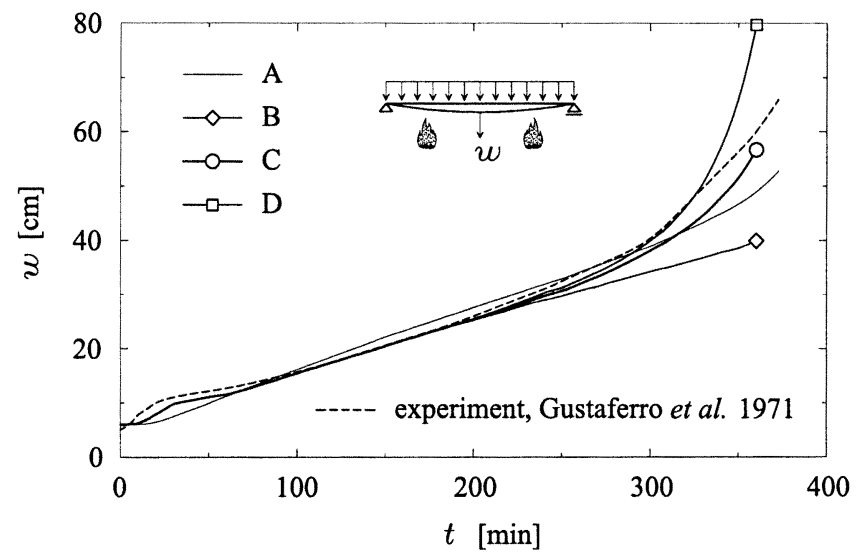

Fig. 8 Vertical displacement at the midspan of the beam

There are substantial disagreements in temperature time graphs between numerical and experimental results at $100^{\circ} \mathrm{C}$ (see Fig. 7). The experiments show that the temperature development is delayed and it resumes the growing trend only after about 30 minutes. The differences between the numerical and measured results is probably caused by the fact, that the structure was not oven-dry before the experiment started. When the temperature of the concrete reached $100^{\circ} \mathrm{C}$, water started to evaporate, for which some amount of heat was consumed. The vapour which developed during the evaporation could not escape from the concrete structure immediately, which prolonged the delay. At this stage of our research, the coupled effect of vapour diffusion and heat conduction including the effect of latent evaporation heat was not possible to be taken into account.

Therefore, in the subsequent numerical analyses, temperatures in the reinforcement bars are taken to be equal to those obtained by the experiment. Fig. 8 shows that, in this case, the calculated vertical displacement at the midspan virtually coincides with the measured one up to about 200 minutes (curves B, C, and D in Fig. 8). Afterwards, the agreement strongly depends on the type of viscous creep in steel considered in the analysis.

If the viscous creep strains in steel are not accounted for, the ultimate vertical displacement at the midspan is much underestimated - only $40.36 \mathrm{~cm}$ or $61 \%$ of the observed ultimate displacement 66 $\mathrm{cm}$ (curve B in Fig. 8). The parameters of viscous creep strain in steel were taken from WilliamsLeir (1983). We employed two types of steel. Using the parameters of medium viscous creep, steel $\mathrm{X}-60$, results in the midspan displacement of $108.23 \mathrm{~cm}$ at time 373 minutes (curve D in Fig. 8). Using the parameters of steel $\mathrm{Au} 50$ that exhibits small viscous creep, gives the ultimate midspan displacement $65.27 \mathrm{~cm}$ at 373 minutes (curve $\mathrm{C}$ in Fig. 8) which agrees well with the experimentally obtained values $(373$ minutes and $66 \mathrm{~cm})$.

Fig. 9 shows the corresponding development of viscous strain for $\mathrm{Au} 50$ steel in the reinforcement bar which is the most exposed to fire. From Fig. 9 it is clearly seen that the viscous creep becomes an important factor once the temperature in the reinforcement reaches about $450^{\circ} \mathrm{C}$ at 200 minutes. The related stress in the bar is also shown in Fig. 9.

Fig. 10 shows the distributions of the calculated temperatures, stresses, mechanical and geometric strains in concrete in the midspan cross-section at time $t=50$ minutes. Due to the non-linear distribution of temperature over the cross-section, considerable gradients of stresses in the cross- 


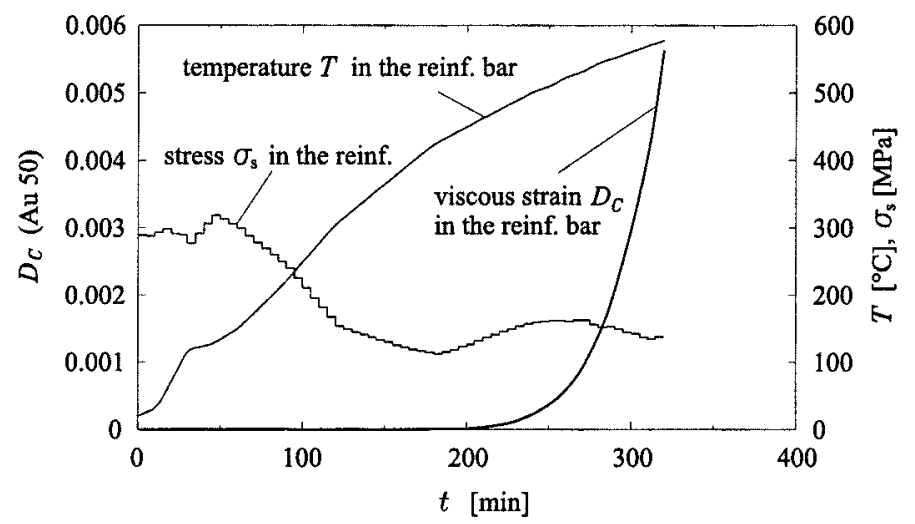

Fig. 9 Viscous strain, temperature and stress developement in the most exposed reinforcement bar

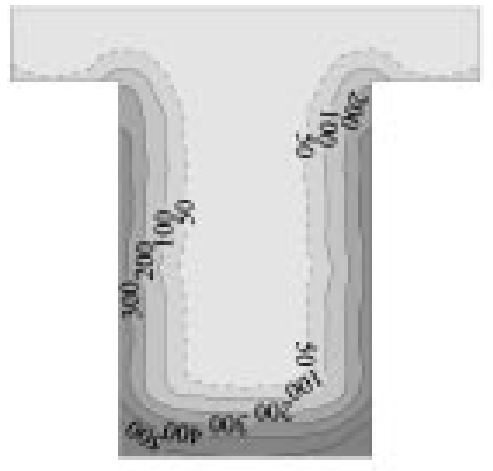

(a)

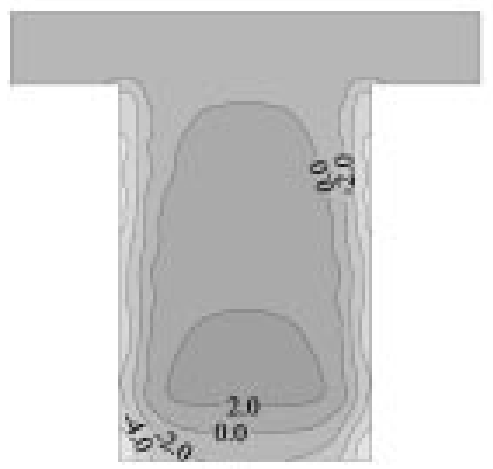

(c)

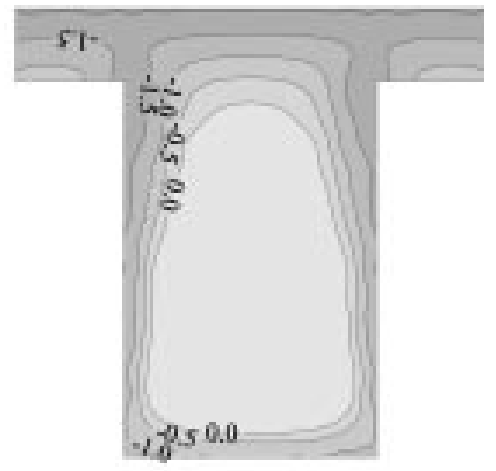

(b)

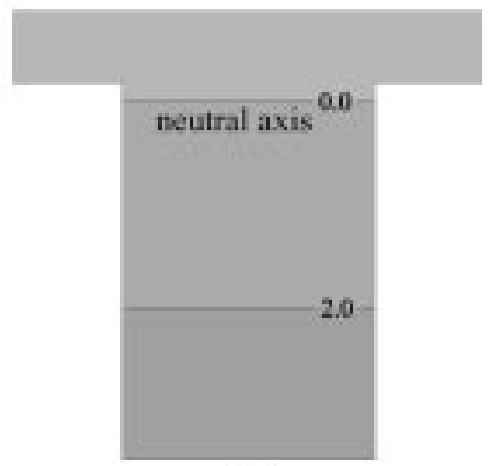

(d)

Fig. 10 (a) Temperature distributions in midspan cross-section at $t=50 \mathrm{~min}\left[{ }^{\circ} \mathrm{C}\right]$, (b) stress distributions in midspan cross-section at $t=50 \mathrm{~min}\left[\mathrm{kN} / \mathrm{cm}^{2}\right]$, (c) mechanical strain distributions in midspan crosssection at $t=50 \mathrm{~min}[\%$ o], (d) geometric strain distributions in midspan cross-section at $t=50 \mathrm{~min}[\%$ o].

section occur, regardless of the fact that the structure is statically determinate. It is interesting to observe the compressive stresses in concrete at the bottom part of the cross-section of the beam. 


\section{Conclusions}

This paper has provided a study of the numerical model for the non-linear analysis of a reinforced concrete beam under fire. Since the interaction between the fire and the structure is a complicated process that is not yet well understood, the analysis is simplified by decomposing the numerical procedure into three separate steps: (i) the determination of fire extent, fire temperature development and duration of fire; (ii) the determination of the temperature distribution in the structure; (iii) the mechanical analysis of the structure. The determination of fire extent was not the subject of the paper. In the thermal analysis, it was assumed that the heat flow in the axial direction of the element was small and performed only 2D thermal transient analysis over the cross-sections. In the mechanical analysis the structure was modelled by high precision, newly developed geometricallyexact planar beam finite elements. The geometric and material non-linearities were considered along with the viscous creep deformation in steel induced by high temperatures.

A relatively good agreement between the numerical results and the results of the full-scale test is obtained. Therefore, it is possible to conclude that the present rather simple 1D mechanical and 2D thermal model seems satisfactory to describe the behaviour of reinforced concrete frames in fire. Further calculations of statically indeterminant structures and their comparisons to full-scale experiments will be addressed elsewhere.

From the comparison between the numerical and experimental results for temperature development with time, it is clear that the effects of evaporization and vapour transport are very important in concrete. As accurate temperature distributions are fundamental for the accuracy of the mechanical analysis, the coupled vapour diffusion and heat conduction problem seems to be required in the analysis of concrete in fire. The softening of concrete in fire conditions is self evident. Its effect on the structural behaviour and, in particular, the appearance of localized zones and the overall softening of the structure, are also very important. These issues will be addressed elsewhere.

\section{References}

Abrams, M.S. (1977), "Performance of concrete structures exposed to fire", Portland Cement Association, Research and Development Bulletin.

Abrams, M.S. (1979), "Behaviour of inorganic materials in fire", ASTM STP 685, Design of Buildings for Fire Safety.

Armer, G.S.T. and O’Dell, T. (1996), "Fire, static, and dynamic tests of building structures", Proc. of 2nd Cardington Conf., E \& FN Spon, London.

ASTM E-119-76 (1976), "Standard methods of fire tests of building construction and materials", Annual Book of ASTM Standards, Parts 18, American Society for Testing and Materials.

Budaiwi, I., El-Diasty, R. and Abdou, A. (1999), "Modelling of moisture and thermal transient behaviour of multilayer non-cavity walls", Building and Environment, 34, 537-551.

Dilger, W.H., Ghali, A., Chan, M., Cheung, M.S. and Maes, M.A. (1983), "Temperature stresses in composite box girder bridges", J. Struct. Eng., ASCE, 109(6), 1460-1478.

Ellingwood, B. and Lin, T.D. (1991), "Flexure and shear behaviour of concrete beams during fires", J. Struct. Eng., ASCE, 117(2), 440-458.

Ellingwood, B. and Shaver, J.R. (1980), "Effects of fire on reinforced concrete members", J. Struct. Div., ASCE, 106(11), 2151-2166.

Eurocode 2 (1995), “Design of concrete structures, Part 1-2: General rules-structural fire design”, ENV 1992-1-2. 
Gustaferro, A.H., Abrams, M.S. and Salse, E.A.B. (1971), "Fire-resistance of prestressed concrete beams, study C: structural behaviour during fire tests", Portland Cement Association, Research and Development Bulletin.

Harmathy, T.Z. (1970), "Thermal properties of concrete at elevated temperatures", J. Materials, 5(1), 47-74.

Huang, Z. and Platten, A. (1997), "Nonlinear finite element analysis of planar reinforced concrete members subjected to fire", ACI Struct. J., 94(3), 272-282.

ISO 834-1 (1999), "Fire-resistance tests - elements of building constructions - Part 1: General requirements".

Lennon, T., Bullock, M.J. and Enjily, V. (2000), "The fire resistance of medium-rise timber frame buildings", Proc. of World Conf. on Timber Engineering, Whistler, BC, Canada, 4.5.4.

Lie, T.T. and Irwin, R.J. (1993), "Method to calculate the fire resistance of reinforced concrete columns with rectangular cross section", ACI Struct. J., 90(1), 52-60.

Lin, T.D., Ellingwood, B. and Piet, O. (1998), "Flexural and shear behaviour of reinforced concrete beams during fire tests", Portland Cement Association, Research and Development Bulletin, Report No. NBS-GCR87-536, Centre for Fire Resarch, National Bureau of Standards, Washington.

Lin, T.D., Gustaferro, A.H. and Abrams, M.S. (1981), "Fire endurance of continuous reinforced concrete beams", Portland Cement Association, Bulletin RD072.01B, Skokie.

Mendes, P.A., Valente, J.C. and Branco, F.A. (2000), "Simulation of ship fire under Vasco da Gama Bridge", ACI Struct. J., 97(2), 285-290.

Nechnech, W., Meftah, F. and Reynouard, J.M. (2002), "An elasto-plastic damage model for plain concrete subjected to high temperatures", Eng. Struct., 24, 597-611.

Özişik, M.N. (1985), Heat Transfer, A Basic Approach, McGraw-Hill Book, Co.

Planinc, I., Saje, M. and Čas, B. (2001), "On the local stability condition in the planar beam finite element", Struct. Eng. Mech., 12(5), 507-526.

Reissner, E. (1972), “On one-dimensional finite-strain beam theory: The plane problem”, J. Applied Mathematics and Physics (ZAMP), 23, 795-804.

Saje, M. and Turk, G. (1987), "HEATC, Computer programme for nonlinear transient heat conduction problems", University of Ljubljana, Faculty of Civil and Geodetic Engineering, Ljubljana.

Saje, M., Planinc, I., Turk, G. and Vratanar, B. (1997), "A kinematically exact finite element formulation of planar elastic-plastic frames", Comput. Methods Appl. Mech. Eng., 144, 125-151.

Sidibé, K., Duprat, F., Pinglot, M. and Bourret, B. (2000), "Fire safety of reinforced concrete columns", ACI Struct. J., 97(4), 642-647.

Srpăč, S. (2000), "Viscous creep of steel structures in fire", J. Applied Mathematics and Mechanics (ZAMM), 80, Suppl. 2, S555-S556.

Vasile, C., Lorente, S. and Perrin, B. (1998), "Study of convective phenomena inside cavities coupled with heat and mass transfer through porous media-application to vertical hollow bricks-a first approach", Energy and Buildings, 28, 229-235.

Williams-Leir, G. (1983), "Creep of structural steel in fire: Analytical expressions”, Fire and Materials, 7(2), 7378. 